\title{
DIAGNÓSTICO DO USO DA ÁGUA SUBTERRÂNEA COMO SUBSÍDIO À GESTÃO MUNICIPAL DE RECURSOS HÍDRICOS
}

Thalita BENETELLO

Sibele EZAKI

\begin{abstract}
RESUMO
A região que abrange as bacias hidrográficas dos rios Piracicaba, Capivari e Jundiaí (PCJ) demonstra uma crescente demanda na explotação e uso das águas subterrâneas, que acompanha o aumento populacional e da urbanização. Levantamentos regionais indicam cenários de limitações na disponibilidade hídrica subterrânea associados a grandes volumes de águas extraídos, mostrando a necessidade de um acompanhamento, também em escala local, sobre a situação do uso dos recursos hídricos. Nesse sentido, este trabalho teve como proposta avaliar os dados existentes e disponíveis sobre a água subterrânea, em escala municipal, com o intuito de elaborar um diagnóstico sobre a sustentabilidade do uso da água. Selecionou-se o município de Sumaré-SP, por estar inserido em área crítica quanto à disponibilidade hídrica e por contemplar no seu Plano Diretor diretrizes para a gestão ambiental integrada. A partir de dados de cadastros oficiais de poços, foram avaliados os aquíferos mais explotados quanto a: potencialidade hídrica (vazões e capacidades específicas médias e medianas, profundidade dos poços e dos níveis d'água), finalidades de uso da água, densidade de poços e intensidade de extração de água subterrânea e saldo hídrico. A constatação de existência de áreas onde ocorre déficit hídrico levou a recomendações como o aprofundamento nos estudos hidrogeológicos, assim como o acompanhamento da evolução da situação da explotação hídrica no município e de ocorrência de conflitos de uso.
\end{abstract}

Palavras-chave: Águas subterrâneas; Gestão municipal de recursos hídricos; Poços; Aquífero Tubarão.

\section{ABSTRACT}

THE EVALUATION OF GROUNDWATER USE APPLIED TO THE MUNICIPAL WATER RESOURCE MANAGEMENT. The region containing the Piracicaba, Capivari and Jundiaí Watershed demonstrates a growing demand for exploration and groundwater use, which accompanies the increase in population and urbanization. Regional surveys indicate a scenario of limitated availability in groundwater associated with the large volumes of water currently being extracted, demonstrating the need for monitoring, on a local sale, the situation of the use of these water resources. Therefore, this study aimed to evaluate available data on groundwater, at a municipal scale, in order to make a diagnosis of the sustainability of water use. The municipality o Sumaré-SP was selected as it is located in a critical area in terms of water availability and because it includes guidelines for integrated environmental management in its Master Plan. Based on data from official registers of wells, the most exploited aquifers were evaluated in terms of their water potential (flows and specific capacities - average and mean; well depth and water levels); the type of water use; density of wells and the intensity of groundwater extraction; water balance. The existence of areas with water deficit led to recommendations such as the improvement of hydrogeological studies, as well as the monitoring of the increase in water exploitation in the city and the occurrence of conflicts of use.

Keywords: Groundwater; Municipal water resource management; Wells; Tubarão Aquifer. 


\section{INTRODUÇÃO}

A escassez hídrica constitui um dos problemas mais debatidos e enfrentados na última década no âmbito de bacias hidrográficas que concentram atividades econômicas e grandes populações, as quais demandam volumes consideráveis de água. O colapso hídrico decorrente do planejamento inadequado na gestão dos recursos hídricos (SOUZA FERNANDES 2015) é, além disso, agravado por fatores associados a mudanças climáticas. Nesse cenário estão inseridas as bacias hidrográficas dos rios Piracicaba, Capivari e Jundiaí (Bacias PCJ), com cerca de 5,8 milhões de habitantes, regiões altamente urbanizadas e industrializadas, mas com disponibilidade hídrica limitada e com histórico de severos comprometimentos, o que é também afetada pela transposição de águas $\left(31 \mathrm{~m}^{3} / \mathrm{s}\right)$ para a Bacia do Alto Tietê, através do Sistema Cantareira (COMITÊS PCJ 2019).

Conforme o Plano das Bacias do PCJ (revisão 2020/2035), no ano de 2018, registrou-se uma demanda de $61,02 \mathrm{~m}^{3} / \mathrm{s}$ para abastecimento público, $16,74 \mathrm{~m}^{3} / \mathrm{s}$ para uso industrial, $5,53 \mathrm{~m}^{3} / \mathrm{s}$ para o setor rural e $6,46 \mathrm{~m}^{3} / \mathrm{s}$ para solução alternativa e outros usos. A disponibilidade de água per capita (superficial e subterrânea), representada pela vazão média em relação à população total, vem apresentando reduções, atingindo um nível crítico de 971,08 $\mathrm{m}^{3}$ /hab/ano (COMITÊS PCJ 2019).

Nesse contexto, a exploração da água subterrânea vem desempenhando um importante papel, dada a grande vocação industrial nas Bacias PCJ, configurando aumento nas demandas constatadas pelo número de perfurações outorgadas. A participação das águas subterrâneas no volume total captado passou de $4,86 \%$ para $10,93 \%$, no período 2010 a 2019 , e a vazão outorgada de $2,59 \mathrm{~m}^{3} / \mathrm{s}$ a $9,64 \mathrm{~m}^{3} / \mathrm{s}$ (COMITÊS PCJ 2015, 2021).

Estudos regionais alertam, entretanto, para a elevada densidade de poços em alguns municípios das Bacias PCJ e grandes volumes de águas extraídos (DAEE/UNESP 2013, IG 2013, HIDROGEOAMBIENTAL 2019, PROFILL 2019), que podem interferir localmente na disponibilidade dos aquíferos. No diagnóstico hidrogeológico das Bacias PCJ, PROFILL (2019) indicou algumas áreas com elevadas densidades de extração de água subterrânea, com valores entre 60 mil e $160 \mathrm{mil} \mathrm{m}^{3}$ / ano $/ \mathrm{km}^{2}$, ao longo do eixo da Rodovia Anhangue$\mathrm{ra}$, abrangendo municípios como Americana, Nova Odessa, Sumaré, Campinas, Hortolândia, Paulínia,
Valinhos, Vinhedo, Capivari, denominando-as como áreas com estresse hídrico.

A intensificação na explotação de recursos hídricos, associada à falta de conhecimento sobre a disponibilidade dos aquíferos, pode ocasionar resultados negativos, expressos na forma de aumento de conflitos e interferências nos usos da água como: rebaixamento dos níveis piezométricos e incremento nos custos de explotação das águas, diminuição das vazões de poços tubulares, supressão ou redução de vazões de corpos de água superficiais e nascentes, abatimentos de terrenos, alteração na qualidade das águas, entre outros, todos agravados em situações de escassez hídrica (FOSTER et al. 2011; SERVMAR/DAEE/IG 2011; DAEE 2015a, b; FRACALANZA \& FREIRE 2016). Além de PROFILL (2019), poucos são os trabalhos sobre os efeitos da superexplotação por poços nas Bacias PCJ, podendo ser citados alguns estudos que indicaram potenciais rebaixamentos do nível d'água no Aquífero Tubarão em Capivari (IRITANI et al. 2009), Rafard, Hortolândia e Tietê (DAEE/IG/IPT/ CPRM 2005).

Ações em recursos hídricos estão atreladas ao modelo de gestão regido por uma legislação que atribui a competência constitucional para legislar sobre águas subterrâneas aos Estados-membros (SOUZA 2012). Assim, não compete ao Município o controle sobre a exploração da água subterrânea, embora seja sua atribuição legislar sobre uso e ordenação do solo, bem como implantar políticas públicas visando medidas de proteção e preservação do manancial hídrico subterrâneo (SOUZA 2012, SANTOS 2013).

Há, entretanto, uma atuação de órgãos gestores municipais, conjuntamente ou não com as instâncias estaduais, no controle do uso da água subterrânea, que normalmente está associada a questões de vigilância da saúde e de exploração da água para abastecimento municipal (prefeituras, concessionárias, etc.). O Plano Municipal de Saneamento Básico (Lei Municipal n ${ }^{\circ} 11.445$, de 05/01/2007), que deve contemplar o serviço básico de fornecimento de água potável, também pode constituir uma ferramenta que contribui com informações sobre o uso da água subterrânea.

Algumas experiências com maior participação municipal podem decorrer da aplicação de legislações ambientais específicas, como por exemplo, na definição de áreas de restrição e controle ao uso e captação de água subterrânea (Deliberação CHR no 52/2005), já aplicada nas regiões de Ribeirão Preto (Deliberação CRH no 165/2014) e São 
Paulo - região de Jurubatuba (Deliberação CRH n ${ }^{\circ}$ 132/2011). Um dos benefícios, além da ampliação e aplicação do conhecimento hidrogeológico na melhoria da gestão dos recursos hídricos, é a sua disseminação nos setores de interesse no âmbito da administração municipal.

Por outro lado, CONICELLI \& HIRATA (2016) e CONICELLI et al. (2021) alertam que o sucesso do gerenciamento das águas subterrâneas deve considerar não apenas a capacidade dos órgãos gestores, mas também o envolvimento da sociedade civil e do setor privado. O usuário necessita ter acesso à informação adequada para que se conscientize sobre quais são os limites sustentáveis de vazão de bombeamento/exploração e compreenda os efeitos de superexplotação dos aquíferos locais. Os autores destacam a importância da articulação entre os diversos atores (dos organismos responsáveis pelo recursos hídricos e usuários) e de uma avaliação crítica das relações institucionais.

Este trabalho tem como proposta abordar, no âmbito do território municipal, o diagnóstico sobre o uso e demanda da água subterrânea, utilizando dados disponíveis de poços profundos. Objetiva-se incentivar um maior aproveitamento desses dados no estabelecimento de diretrizes que contribuam para o uso sustentável dos recursos hídricos subterrâneos em nível municipal. O município de
Sumaré, no âmbito das Bacias PCJ (Figura 1), foi selecionado pelo critério de estar inserido em área crítica diagnosticada por DAEE/UNESP (2003) e PROFIL (2019) e por contemplar no seu Plano Diretor restrição da ocupação urbana em área de proteção de mananciais.

\section{2 ÁREA DE ESTUDO}

O município de Sumaré apresenta em seu Plano Diretor Municipal (Lei Municipal no 4.250, de 6 de outubro de 2006) diretrizes para a gestão ambiental integrada às políticas de desenvolvimento que incorporam: "os recortes territoriais das bacias hidrográficas nos seus estudos e avaliações; a priorização na implementação de ações que levem à mitigação de processos de degradação ambiental decorrentes de usos e ocupações incompatíveis e das deficiências de saneamento ambiental". Dentre as diretrizes para a gestão do patrimônio ambiental no território municipal de Sumaré está contemplada a recuperação e adequação de áreas ambientalmente frágeis e de preservação permanente, especialmente em recarga dos aquíferos, e a restrição da ocupação urbana em áreas de proteção de mananciais e de recarga dos aquíferos, bem como dos locais de captação superficial de água (PREFEITURA MUNICIPAL DE SUMARÉ 2006). No

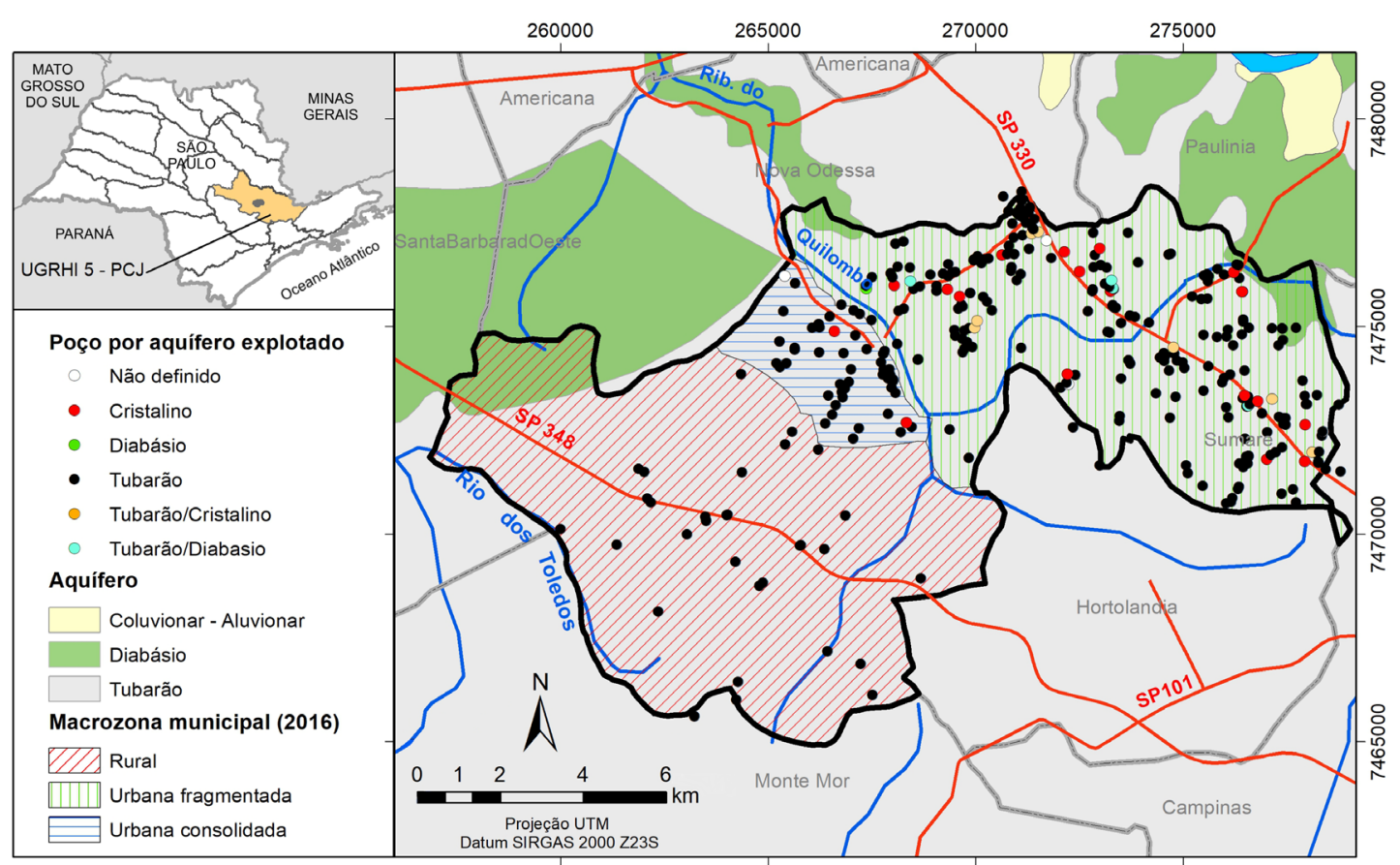

FIGURA 1 - O município de Sumaré no âmbito das bacias PCJ e a distribuição dos poços tubulares profundos identificados pelo aquífero explotado. 
Plano Diretor é definido o macrozoneamento municipal, que tem como objetivo, entre outros, limitar o crescimento urbano em regiões não propícias à urbanização e naquelas de reconhecida qualidade ambiental a ser preservada ou restabelecida.

A área do território municipal de Sumaré corresponde a $153.465 \mathrm{~km}^{2}$ e a população estimada é de 282.441 pessoas para o ano de 2019 (IBGE 2019); apresenta elevado grau de urbanização $(98,82 \%)$ e $98,10 \%$ da população conta com abastecimento de água. O município insere-se no contexto da Região Metropolitana de Campinas, com intenso desenvolvimento industrial nas últimas décadas, que favoreceu o crescimento do segmento comércio e prestação de serviços. Apesar disso, a agricultura também se destaca, com produção de cana-de-açúcar, principalmente, e subordinadamente de tomate, milho, batata inglesa, soja e feijão (PREFEITURA MUNICIPAL DE SUMARÉ 2019 a).

A principal fonte de abastecimento público da população urbana é superficial e o sistema produtor municipal é constituído de duas estações de captação de água, a ETA I e ETA II, situadas respectivamente, nas regiões administrativas Centro (Vila Miranda) e Maria Antônia (Parque Itália). A ETA I produz cerca de $542 \mathrm{~L} / \mathrm{s}$ e é abastecida pelas represas Marcelo Pedroni, Horto I e Horto II, que por sua vez, reservam águas, respectivamente, do Córrego Pinheirinho, Ribeirão Jacuba e córregos Taquara Brana e Bassos. Já a ETA II produz 750 $\mathrm{L} / \mathrm{s}$ e está vinculada à captação no Rio Atibaia, em Paulínia. O município também importa água, em média $150 \mathrm{~L} / \mathrm{s}$, de concessionária (PREFEITURA MUNICIPAL DE SUMARÉ 2019b).

O volume de água superficial potável corresponde a cerca de $97,3 \%$ do total produzido (média no período de 2011 a 2018), sendo $2,7 \%$ provenientes dos aquíferos. Em 2018, o total de volume produzido por BRK Ambiental - Sumaré S.A foi de $21.509 .720 \mathrm{~m}^{3}$, sendo $99,43 \%$ dos mananciais superficiais e $0,57 \%$ subterrâneos (SNIS 2020). Os poços destinados ao abastecimento público encontram-se na área rural do município.

\section{METOdologia}

O trabalho fundamenta-se, primordialmente, em registros de dados de poços tubulares existentes no município, que foram levantados em cadastros oficiais estadual e federal. Após a etapa de levantamento, procedeu-se a avaliação de informações disponíveis e de interesse, como os dados cons- trutivos de poços, litoestratigráficos, hidráulicos e regime de exploração da água, que culminou com a elaboração de um banco de dados. Tratamentos e análises desses dados contribuíram para um diagnóstico sobre o aproveitamento de aquíferos e demandas e uso da água subterrânea, referenciando essas informações com a área territorial do município de Sumaré.

\subsection{Levantamento de dados de poços profundos}

Os dados sobre poços tubulares foram obtidos nos bancos de dados do Departamento de Águas e Energia Elétrica (DAEE): (a) Sistema de Outorga Eletrônica (SOE) (http://sibh.daee.sp.gov. br/outorgas); (b) Sistema de Informações de Águas Subterrâneas - SIDAS (Anexo VII da Portaria DAEE 717/96, de 12/12/96), correspondente a um sistema de informação da PRODESP FCHE, que recebeu dados até o ano 2017; (c) Outorga - Pesquisa de Dados dos Recursos Hídricos do Estado de São Paulo: consulta online por município ou por UGRHI (http://www.aplicacoes.daee.sp.gov. br/usosrec/fchweb.html), vinculado ao cadastro PRODESP-FCHE. Também foram consultados registros do Sistema Integrado de Informações ao Cidadão (SIC), cadastrados para cobrança pelo uso da água, junto à Agência das Bacias PCJ, e do Sistema de Informações de Águas Subterrâneas (SIAGAS), gerenciado pelo Serviço Geológico do Brasil (CPRM) (http://siagasweb.cprm.gov.br/). Foram realizadas pesquisas no site do Diário Oficial do Estado de São Paulo, como complementação às informações dos cadastros citados.

As informações foram organizadas em um banco de dados e avaliadas de forma a verificar erros relacionados à duplicidade, coordenada ou demais informações inconsistentes. A diferença na estrutura e conteúdo dos cadastros consultados levou à separação dos dados em duas partes, sendo uma delas associada a informações sobre vazões outorgadas e finalidade de uso da água; e a outra, a características construtivas dos poços, litológicas e dados hidráulicos.

\section{Vazão explotada (diária e anual)}

Para estimar a produção de água e captação de volumes, foram utilizados dados de poços constantes no Banco de Dados do SOE e pela consulta no site do DAEE por município (PRODESP FCHE). Foram extraídas informações sobre vazão outorgada $\left(\mathrm{m}^{3} / \mathrm{h}\right)$, regime de bombeamento (hora/ dia, dia/mês, mês/ano), coordenada geográfica, fi- 
nalidade de uso da água e aquífero explotado. Para os registros sem informação de regime de bombeamento de dia/mês ou mês/ano, consideraram-se, respectivamente os valores de 30 (dias) e 12 (meses).

Foram considerados e agrupados os seguintes aquíferos explotados: Tubarão (Tubarão, Tatuí e Itararé), Diabásio (Intrusiva e Serra Geral), Cristalino, Poços Mistos (que captam água em mais de um aquífero, p.ex. Tubarão/Cristalino, Tubarão/ Diabásio) e "Sem informação" (dados de vazão contemplados apenas na explotação total no município). O Aquífero Freático não foi considerado para cálculo das vazões outorgadas explotadas.

\section{Profundidade de poços e níveis estáticos}

Dados de profundidade do poço, de nível estático (NE) e de nível dinâmico (ND) foram compilados do banco de dados do SIDAS e SIAGAS, e complementados com levantamentos realizados pelo Instituto Geológico em empresas de perfuração. Nos registros com mais de um teste de vazão (vazão, NE e ND) ou profundidade alterada, foram considerados os dados mais recentes.

3.2 Caracterização da potencialidade dos aquíferos explorados e do uso da água subterrânea

A potencialidade dos aquíferos foi caracterizada a partir da vazão e da capacidade específica dos poços cadastrados por DAEE (SIDAS) e CPRM (SIAGAS), uma vez que o cadastro SOE não possui informações disponíveis com este detalhamento. Um perfil das principais finalidades de uso da água subterrânea e da captação foi elaborado por aquífero explorado, visando conhecer as demandas no município.

Mapas temáticos de densidade de poços e vazões anuais outorgadas foram confeccionados para avaliar a situação dos aquíferos frente à exploração de água subterrânea. Utilizaram-se ferramentas de análise geoestatística para cálculo da densidade de pontos e interpolação de capacidades específicas, pelo método do inverso da distância ponderada (IDW - Inverse Distance Weighting), com o programa ArcGIS versão 10.7.1 (ESRI 2019). Para a execução de interpolações, o limite de município foi extrapolado, tendo sido utilizados dados de municípios vizinhos, quando disponíveis.

Adotou-se o conceito e metodologia de determinação do saldo (ou estresse) hídrico, desenvolvido por PROFILL (2019) e PAULA E SILVA et al. (2021) no diagnóstico hidrogeológico das Bacias
PCJ. O saldo hídrico considera a diferença entre os volumes de água subterrânea disponíveis e os volumes extraídos por poços, e corresponde ao quanto resta de água para uso. Uma situação de estresse representa demandas por água maiores do que as quantidades disponíveis para uso. $\mathrm{O}$ indicador utilizado para representar a disponibilidade hídrica subterrânea foi a vazão mínima de referência $Q_{95}$ (vazão mínima de permanência com frequência de $95 \%$ do tempo).

Os valores de disponibilidade por sub-bacias foram obtidas de DAEE/UNESP (2013), em formato shapefile, com vazões mínimas $\mathrm{Q}_{95}$ variando de 4,651 a 4,685 L/s/ $\mathrm{km}^{2}$ no município de Sumaré. Converteu-se a disponibilidade para $\mathrm{m}^{3} / \mathrm{ano} / \mathrm{km}^{2}$, considerando, também, tamanho de células de 200 x $200 \mathrm{~m}$, em formato raster.

Os valores extraídos por poços outorgados foram representados pelo mapa de vazões anuais ( $\left.\mathrm{m}^{3} / \mathrm{ano}\right)$. Calculou-se a densidade de vazão anual específica, com a função Kernel, com espacialização em células de $200 \times 200$ m, de modo a se obter valores $\mathrm{em} \mathrm{m}^{3} / \mathrm{ano} / \mathrm{km}^{2}$, também em formato raster. A subtração da disponibilidade pela vazão explorada, utilizando tanto os programas QGIS 3.10.9 with GRASS 7.8.3, como Arc GIS versão 10.7.1., resultou no mapa de saldo (estresse) hídrico.

\section{RESULTADOS E DISCUSSÃO}

\subsection{Banco de dados de poços}

Com a atualização de procedimento para obtenção de outorga de direito de uso da água subterrânea, pelas Portarias DAEE n 1.630/2017 e $\mathrm{n}^{\circ} 1.631 / 2017$, os poços passaram a ser cadastrados no banco de dados SOE, a partir de março de 2017, com redução significativa das informações e desvinculadamente ao sistema anterior, o SIDAS. O banco de dados SIDAS, gerenciado pela PRODESP, permitia a consulta dos dados de poços considerando o identificador (número da folha topográfica IBGE e número sequencial de cadastro), seja por município e por UGHRI.

O levantamento totalizou 286 poços outorgados ou com dispensa de outorga, ou seja, que possuem algum tipo de autorização para explotação de água. Deste total, 225 poços $(78,67 \%)$ explotam o Aquífero Tubarão, 18 poços $(6,29 \%)$ o Cristalino, 7 poços $(2,45 \%)$ são mistos (3 do Tubarão/Cristalino e 4 do Tubarão/Diabásio), e 2 explotam o Diabásio (Figura 1). Outros 21 poços $(7,34 \%)$ explotam o Freático e $13(4,5 \%)$ não foram definidos. 
Grande quantidade dos poços concentra-se nas porções centro-norte e leste do município, nas macrozonas urbanas consolidada e fragmentada, mas está também alinhada às principais estradas (Figura 1). A macrozona consolidada corresponde a grande parte da Região Administrativa AR1-Sede do município (Figura 2), onde predominam atividades de comércio e serviços (vide Mapa 20 - Localização Industrial, Prestação de Serviços e Comércio, da Revisão do Plano Diretor do Município de Sumaré) (PREFEITURA MUNICIPAL DE SUMARÉ 2019c).

$\mathrm{Na}$ macrozona urbana fragmentada, na porção norte do município, limite entre as regiões administrativas Picerno (AR-6) e Nova Veneza (AR2), está a estrada marginal (Variante Anhanguera), ao longo da qual estão instaladas inúmeras indústrias, até sua ligação com a Rodovia Anhanguera (SP-300), onde há um adensamento dos poços (Figuras 1 e 2). A sul da Avenida Amizade, na região administrativa Nova Veneza (AR-2), observa-se também adensamentos urbanos e de poços.

Ao longo da Rodovia Anhanguera, nas quatro regiões administrativas situadas na porção norte-leste do município (Nova Veneza AR-2; Maria Antonia AR-5; Área Cura - Comunidade Urbana de Recuperação Acelerada AR-4; Matão AR-3), a concentração de poços está relacionada a um con- junto de indústrias, mas também a serviços. Os poços se adensam, também, ao longo de avenidas principais, como por exemplo, Av. Emílio Bosco e Av. Minasa, na AR3-Matão, com ocupações urbanas mistas (indústria, serviço, residência) (PREFEITURA MUNICIPAL DE SUMARÉ 2019a, c).

Tal adensamento de poços pode ser melhor observado quando representado em células de 1000 m X 1000 m (Figura 3), chegando a agrupar 12 poços por $\mathrm{km}^{2}$. Para ODA et al. (2005) e DAEE/IG/IPT/CPRM (2005), que propuseram um Mapa de Vazão Recomendada para exploração do Sistema Aquífero Tubarão no Estado de São Paulo, a distribuição ideal entre poços para o Aquífero Tubarão é de 4 poços por $\mathrm{km}^{2}$, considerando um uso sustentável numa situação de recarga de 0,25 $\mathrm{m} /$ ano, poços com $150 \mathrm{~m}$ de profundidade, capacidade específica de $0,1 \mathrm{~m}^{3} / \mathrm{h} / \mathrm{m}$ e rebaixamento de nível d'água de $30 \mathrm{~m}$ durante o bombeamento de poços com vazões de cerca de $3 \mathrm{~m}^{3} / \mathrm{h}$. O aumento de poços nessas células de $1 \mathrm{~km}^{2}$ implicaria a redução da vazão de cada poço.

\subsection{Potencialidades dos aquíferos explorados}

A caracterização dos aquíferos neste trabalho baseia-se em dados obtidos a partir de sondagens e perfuração de poços e de mapeamentos geológicos. Informações essenciais são obtidas em relatórios

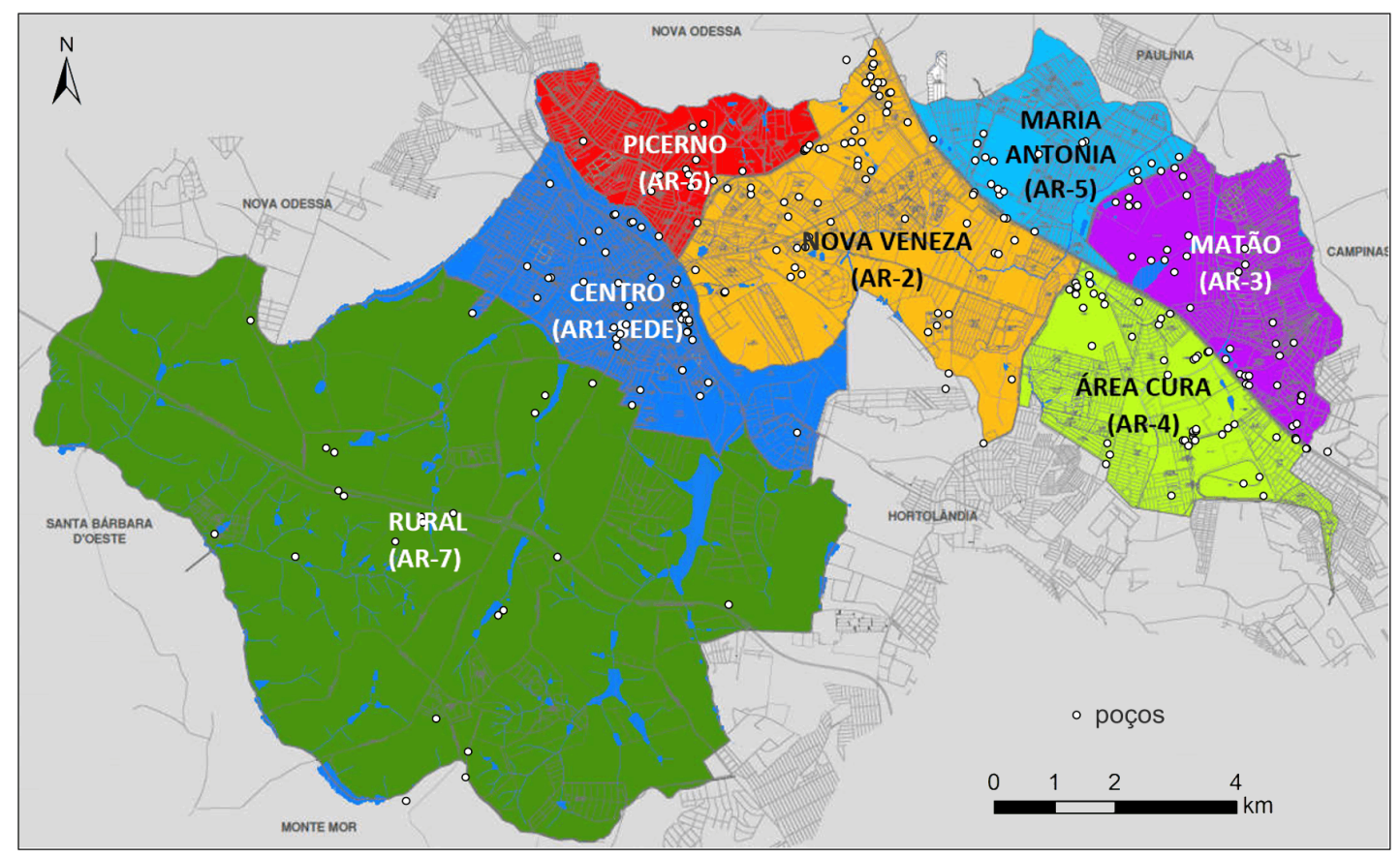

FIGURA 2 - Mapa das administrações regionais do Município de Sumaré - Mapa 10. (Extraído de PREFEITURA MUNICIPIAL DE SUMARÉ 2019c). 


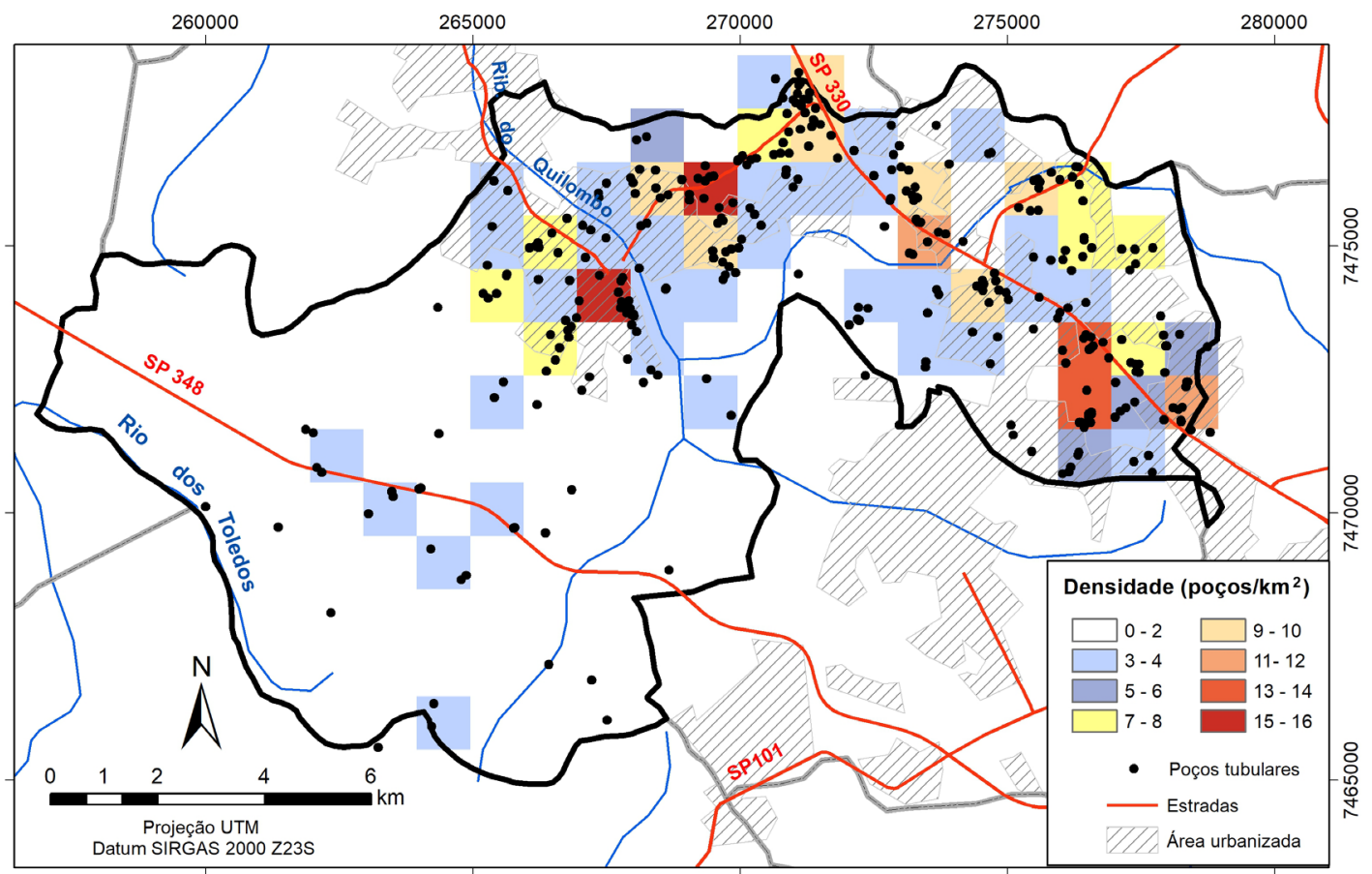

FIGURA 3 - Densidade de poços tubulares em Sumaré, utilizando os bancos de dados do SOE e DAEE-municípios.

de poços com a descrição litoestratigráfica e dados construtivos e de testes de vazão. Algumas dessas informações foram extraídas do cadastro de poços do SIDAS (DAEE) para se obter características básicas dos aquíferos em Sumaré, como profundidade dos poços, níveis estático e dinâmico, vazão do teste e capacidade específica.

Os poços tubulares apresentam profundidades médias em torno de $185 \mathrm{~m}$, mas também atingem valores elevados com cerca de $400 \mathrm{~m}$ no Tubarão e 430 m em Poços Mistos. Os níveis estáticos (NE) nos aquíferos Tubarão e Cristalino são mais profundos, com médias em torno de $35 \mathrm{~m}$, mas a mediana para todos os aquíferos é cerca de
$30 \%$ menor em relação à média. Ocorre grande discrepância com relação aos máximos valores de NE encontrados, atingindo quase $200 \mathrm{~m}$ no Aquífero Tubarão (Tabela 1).

O Aquífero Tubarão é do tipo poroso, associado a descontinuidades estruturais (juntas e fraturas), livre, mas localmente semi-confinado ou confinado, pela disposição irregular de rochas sedimentares finas (ritmito, siltito e folhelho) de baixa permeabilidade em meio a outros tipos litológicos, que dificultam o fluxo da água, conferindo-lhe características anisotrópicas (DAEE 1981). Regionalmente, este aquífero é um reservatório subterrâneo de produtividade limitada, com vazões

TABELA 1 - Profundidades e níveis estáticos, médios e medianos, dos poços dos Aquíferos Tubarão, Cristalino, Diabásio e poços mistos.

\begin{tabular}{ccccccccccc}
\hline $\begin{array}{c}\text { Aquifero } \\
\text { explotado }\end{array}$ & \multicolumn{4}{c}{ Profundidade dos Poços $(\mathrm{m})$} & \multicolumn{5}{c}{ Nivel Estático $(\mathrm{m})$} \\
\hline & $n^{*}$ & Média & Mediana & Mín. & Máx. & $n^{*}$ & Média & Media- & Mín. & Máx. \\
\hline Tubarão & 153 & 178,0 & 165,0 & 40,0 & 430,0 & 153 & 34,4 & 24,9 & 0,0 & 186,0 \\
Cristalino & 7 & 182,6 & 170,0 & 102,0 & 302,0 & 7 & 36,8 & 24,1 & 5,0 & 102,0 \\
Diabásio & 6 & 196,7 & 154,0 & 127,0 & 341,5 & 6 & 15,0 & 11,5 & 1,0 & 39,6 \\
Poços Mistos & 51 & 183,3 & 178,5 & 59,0 & 400,0 & 51 & 20,4 & 15,6 & 1,0 & 80,0 \\
Média & & 185,2 & 166,9 & 82,0 & 368,4 & & 26,7 & 19,0 & 1,8 & 101,9 \\
\hline
\end{tabular}

$\mathrm{n} *$ : número de registros utilizados 
inferiores a $10 \mathrm{~m}^{3} / \mathrm{h}$ (DAEE/IG/IPT/CPRM 2005, ODA et al. 2012), devido à heterogeneidade litológica, contendo localmente áreas de maior potencial em bolsões arenosos.

O Aquífero Diabásio é constituído de rochas intrusivas básicas e ocorre de forma irregular, atravessando o Aquífero Tubarão na forma de sills ou diques de diabásio.

O Aquífero Cristalino corresponde ao Embasamento Cristalino, sotoposto ao Aquífero Tubarão, sendo constituído por rochas ígneas e metamórficas. A circulação e armazenamento de água nos aquíferos Cristalino e Diabásio ocorrem atra- vés de fraturas nas rochas ou em seus mantos de alteração (DAEE 1981).

Conforme esperado, as vazões médias de testes encontradas nos poços de Sumaré são baixas para todos os aquíferos (Tabela 2, Figura 4). No Aquífero Tubarão as vazões média e mediana são, respectivamente $7,76 \mathrm{~m}^{3} / \mathrm{h}$ e $5,00 \mathrm{~m}^{3} / \mathrm{h}$, podendo atingir valores elevados, na faixa de $50 \mathrm{~m}^{3} / \mathrm{h}$. Estes valores mais elevados podem estar associados a bolsões arenosos com espessuras saturadas que permitem manter esta vazão de exploração. Não se constatou um padrão de ocorrência dessas maiores vazões no município, podendo inclusive, ocorrer

TABELA 2 - Vazões de testes e capacidades específicas dos aquíferos Tubarão, Cristalino, Diabásio e poços mistos em Sumaré, considerando o banco de dados do IG e dos SIDAS.

\begin{tabular}{|c|c|c|c|c|c|c|c|c|c|c|}
\hline \multirow{2}{*}{$\begin{array}{l}\text { Aquifero } \\
\text { explotado }\end{array}$} & \multicolumn{5}{|c|}{$\operatorname{Vazão}\left(\mathrm{m}^{3} / \mathrm{h}\right)$} & \multicolumn{5}{|c|}{ Capacidade Especifica - $Q / s\left(m^{3} / h / m\right)$} \\
\hline & $n$ & Média & Mediana & Min. & Máx. & $n$ & Média & Mediana & Min. & Máx. \\
\hline Tubarão & 123 & 7,76 & 5,00 & 0,29 & 49,50 & 123 & 0,24 & 0,09 & 0,00 & 3,86 \\
\hline Cristalino & 6 & 8,97 & 7,50 & 2,50 & 19,80 & 6 & 0,41 & 0,28 & 0,01 & 1,35 \\
\hline Diabásio & 6 & 5,33 & 3,48 & 1,02 & 12,00 & 6 & 0,10 & 0,03 & 0,01 & 0,29 \\
\hline Misto & 39 & 4,92 & 3,98 & 0,10 & 16,85 & 39 & 0,09 & 0,05 & 0,00 & 0,52 \\
\hline Total & 174 & & & & & & & & & \\
\hline Média geral & & 6,75 & 4,99 & 0,98 & 24,54 & 174 & 0,21 & 0,11 & 0,01 & 1,51 \\
\hline
\end{tabular}

n: número de registros utilizados

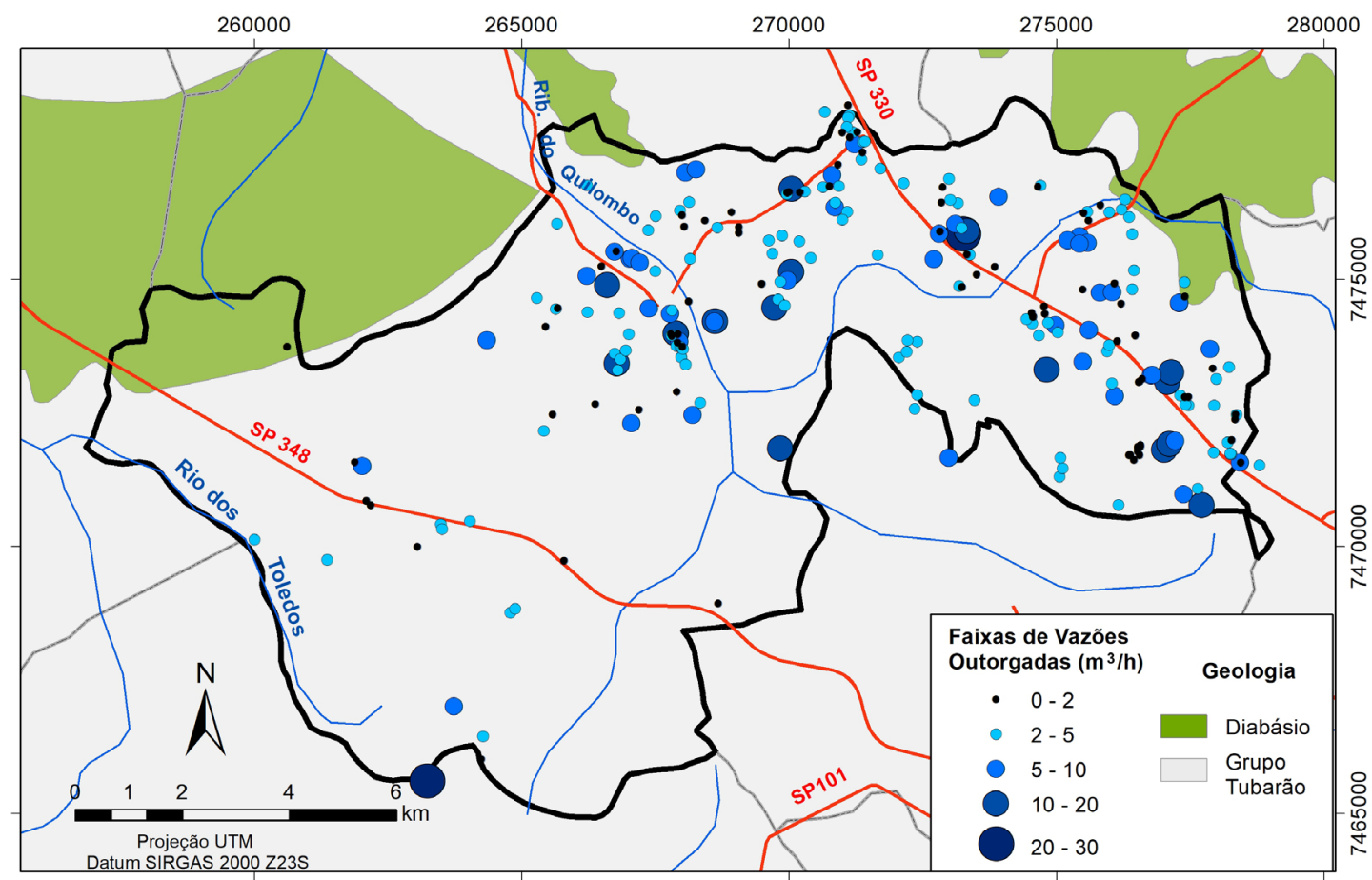

FIGURA 4 - Distribuição das classes de vazões para poços tubulares de Sumaré, considerando o banco de dados do SIDAS-DAEE. 
poços muito próximos com vazões variadas (Figura 3).

A capacidade específica $(\mathrm{Q} / \mathrm{s})$ do Aquífero Tubarão no Estado de São Paulo varia de 0,02 a $4,67 \mathrm{~m}^{3} / \mathrm{h} / \mathrm{m}$ e apresenta, respectivamente, média e mediana de $0,30 \mathrm{~m}^{3} / \mathrm{h} / \mathrm{m}$ e $0,11 \mathrm{~m}^{3} / \mathrm{h} / \mathrm{m}$ (DAEE/ IG/IPT/CPRM 2005). Na Região Administrativa de Campinas varia de 0,002 a 7,5 $\mathrm{m}^{3} / \mathrm{h} / \mathrm{m}$ (DAEE 1981). Em Sumaré os valores médio e mediano de $\mathrm{Q} / \mathrm{s}$ são, respectivamente, $0,24 \mathrm{~m}^{3} / \mathrm{h} / \mathrm{m}$ e 0,09 $\mathrm{m}^{3} / \mathrm{h} / \mathrm{m}$ (Tabela 2), próximos aos valores regionais para este aquífero. Poços no Aquífero Diabásio e Mistos apresentam valores médios de $\mathrm{Q} / \mathrm{s}$ inferiores (cerca de $0,1 \mathrm{~m}^{3} / \mathrm{h} / \mathrm{m}$ ), ao contrário do Aquífero Cristalino que apresenta valores superiores (média de $0,41 \mathrm{~m}^{3} / \mathrm{h} / \mathrm{m}$ ).

Nas porções com maior concentração de poços e informações sobre capacidade específica é possível identificar as áreas com maior potencialidade em termos de produção de água subterrânea, que correspondem a manchas de tonalidade azul mais escura (a leste do município) (Figura 5). A interpolação de dados de poços isolados e escassos, a oeste e a sul, na área rural, podem conduzir a uma interpretação equivocada sobre as produtividades dos aquíferos em locais sem informações, devendo ser interpretadas cuidado- samente. O refinamento desta informação só pode ser obtido com a incorporação de dados futuros de testes de vazão, em caso de perfuração de poços.

\subsection{Uso da água subterrânea}

O aquífero mais explorado em Sumaré, em termos de volumes diários e anuais, é o Aquífero Tubarão (cerca de $80 \%$ ), seguido do aquífero Cristalino (cerca de 8,0\%) e de poços mistos (Tubarão/Cristalino e Tubarão/Diabásio) (4,2\%) e não definidos (6,3\%) (Tabela 3 ).

Ao se avaliar os volumes de água subterrânea outorgados por finalidade de uso, constata-se que a principal demanda municipal é industrial/sanitária. Cerca de $25 \%$ dos poços outorgados em Sumaré com esta finalidade de uso utilizam $40 \%$ do volume de água captado dos aquíferos. Poços destinados ao uso sanitário e industrial (processo) correspondem a $44 \%$ e $23 \%$, respectivamente, do total, e somados, produzem $46 \%$ do volume de água subterrânea diário, enquanto poços destinados à irrigação e dessedentação não possuem volumes consideráveis (Tabela 4, Figura 6). Isso demonstra que a captação da água subterrânea tem significativa importância para o setor produtivo municipal, tanto industrial, como de serviços.

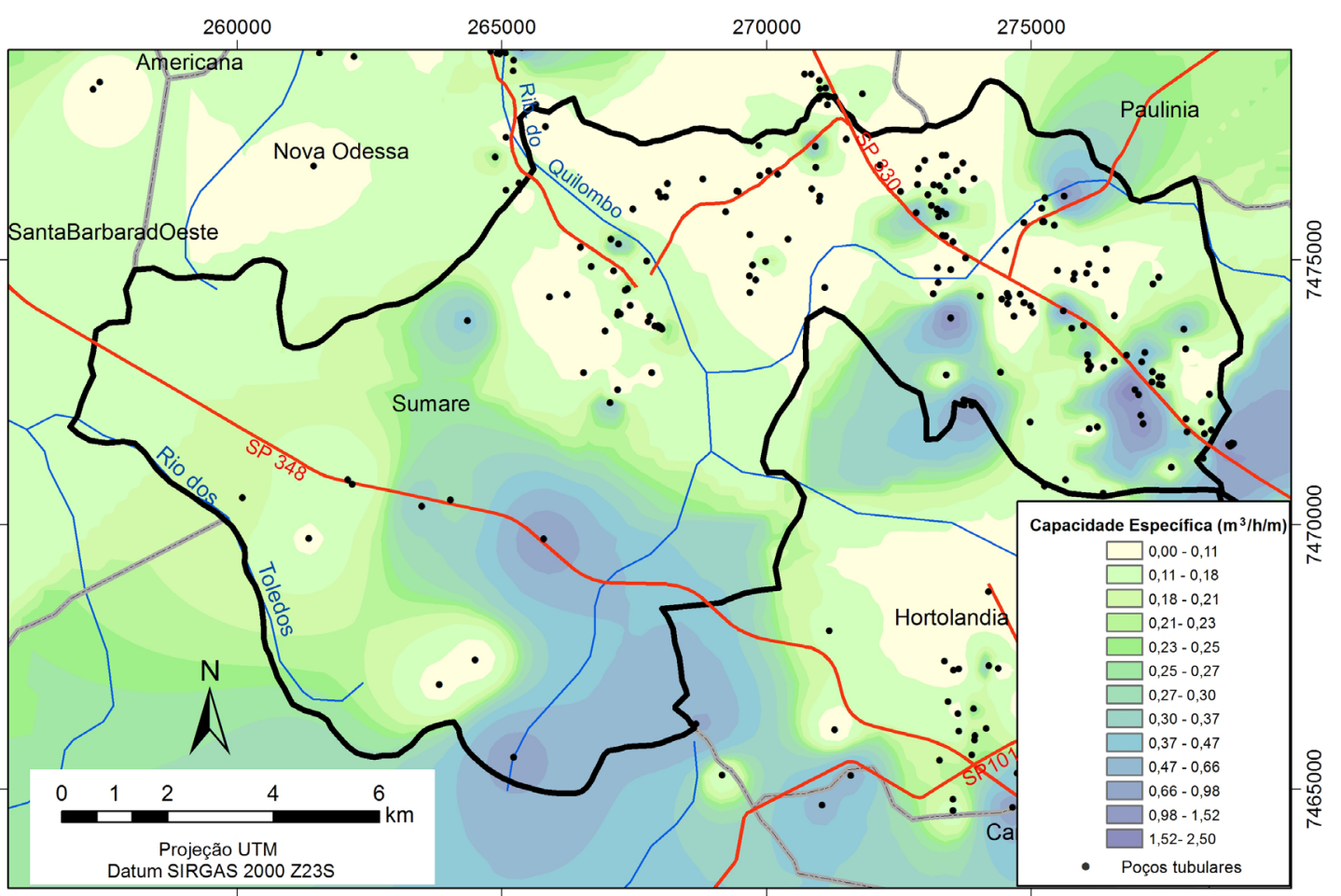

FIGURA 5 - Mapa de isovalores de capacidade específica dos aquiferos em Sumaré, considerando o banco de dados do SIDAS-DAEE. 
TABELA 3 - Volumes diários e anuais de água subterrânea explotados por aquífero em Sumaré, com base nos dados do SOE e DAEE-municípios.

\begin{tabular}{lcrcrc}
\hline \multirow{2}{*}{ Aquifero } & Total de & \multicolumn{5}{c}{ Volume explotado } \\
\cline { 3 - 6 } & Poços & \multicolumn{1}{c}{$m^{3} /$ dia } & $\%$ & \multicolumn{1}{c}{$m^{3} /$ ano } & $\%$ \\
\hline Tubarão & 214 & $11.778,5$ & 79,8 & $4.149 .969,6$ & 80,0 \\
Diabásio & 2 & 72,0 & 0,5 & $25.920,0$ & 0,5 \\
Cristalino & 18 & $1.186,9$ & 8,0 & $414.042,0$ & 8,0 \\
Misto & 7 & 795,0 & 5,4 & $265.980,0$ & 5,1 \\
Não Definido & 21 & 922,2 & 6,3 & $331.980,0$ & 6,4 \\
\hline TOTAL & 262 & $14.754,6$ & 100 & $5.187 .891,6$ & 100,0 \\
\hline
\end{tabular}

TABELA 4 - Volumes de água subterrânea explotados por finalidades de uso em Sumaré, com base nos dados do SOE e DAEE-municípios.

\begin{tabular}{cccccrc}
\hline $\begin{array}{c}\text { Finalidade de uso da } \\
\text { água }\end{array}$ & $\begin{array}{c}\text { Quantidade } \\
\text { de poços }\end{array}$ & $\%$ & $\begin{array}{c}\text { Volumes } \\
\text { diários } \\
\left(\mathrm{m}^{3} / \text { dia }\right)\end{array}$ & $\%$ & $\begin{array}{c}\text { Volumes } \\
\text { anuais } \\
\left(\mathrm{m}^{3} / \text { ano }\right)\end{array}$ & $\%$ \\
\hline Dessedentação & 3 & 1,13 & 115,44 & 0,75 & $41.558,40$ & 0,80 \\
Irrigação & 2 & 0,75 & 13,00 & 0,08 & $3.528,00$ & 0,07 \\
Outras & 2 & 0,75 & 143,60 & 0,93 & $51.696,00$ & 1,00 \\
Abastecimento Público & 5 & 1,89 & 679,07 & 4,39 & $244.464,00$ & 4,71 \\
Transporte Água & 8 & 3,02 & 637,33 & 4,12 & 229440,00 & 4,42 \\
Industrial & 62 & 23,40 & $3.391,56$ & 21,91 & $1.161 .846,00$ & 22,40 \\
Sanitário & 118 & 44,53 & $3.846,57$ & 24,85 & $1.372 .820,40$ & 26,46 \\
Industr./Sanit. & 65 & 24,53 & $6.652,84$ & 42,98 & $2.082 .538,80$ & 40,14 \\
\hline TOTAL & 265 & 100,00 & $15.479,41$ & 100,00 & $5.187 .891,60$ & 100,00 \\
\hline
\end{tabular}

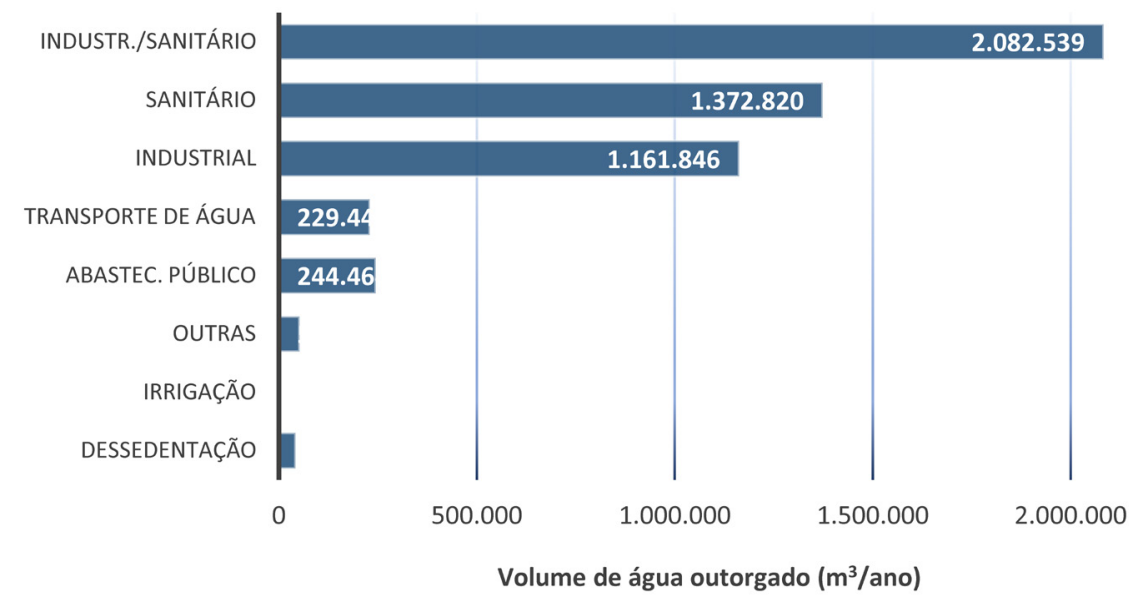

FIGURA 6 - Distribuição do volume anual de água subterrânea explotada em Sumaré de acordo com a finalidade de uso, com base nos dados do SOE e DAEE-municípios.

Vale destacar que apenas $4,39 \%$ do volume diário de água explotada é destinado ao abastecimento público, totalizando $679,07 \mathrm{~m}^{3} / \mathrm{dia}$. Considerando a estimativa de consumo médio per capita para residências (de 70 a $120 \mathrm{~L} /$ dia) da população (SABESP 2017), o consumo diário municipal deve variar de $19.777,87 \mathrm{~m}^{3}$ a $33.892,92 \mathrm{~m}^{3}$. Isso demonstra que a produção dos aquíferos com a fi- 
nalidade de abastecimento público responde por $2,00 \%$ a $3,43 \%$ do esperado, sendo a maior contribuição proveniente das captações superficiais.

A figura 7 apresenta um mapa de vazões anuais extraídas por poços em Sumaré, demonstrando os locais onde há maior intensidade de explotação de águas subterrâneas, com extrações de volumes que chegam a 150.000 a $203.000 \mathrm{~m}^{3} /$ ano. Pontualmente, os locais onde ocorre maior exploração não correspondem, necessariamente, àqueles que apresentam maior potencial produtivo em termos de capacidade específica (vide figura 5).

Ao se avaliar a densidade das vazões extraídas por áreas, representadas por células de $200 \mathrm{x}$ $200 \mathrm{~m}$, constata-se que as áreas de ocorrência de maior exploração de água subterrânea (em termos de volumes anuais) correspondem às áreas de sobreposição dos raios de influência de poços explorados (em bombeamento). A figura 8 destaca tais áreas (em laranja e vermelho) com maiores densidades de vazão $\left(\mathrm{m}^{3} / \mathrm{ano} / \mathrm{km}^{2}\right)$, que merecem atenção no sentido de acompanhamento das extrações de água subterrânea, em especial, às ocorrências ou indícios de interferência entre poços, queda dos níveis d'água ao longo do tempo, diminuição de produtividade relacionada a algum evento pontual ou regional, entre outros. São áreas com características de ocupação urbana industrial, mas também voltada aos serviços e residencial (baixo a alto padrão), principalmente, nas regiões administrativas de Maria Antonia (AR-5), Nova Veneza (AR-2), Área Cura (AR-4), Matão (AR-3) e Sede (AR-1).

$\mathrm{Na}$ figura 9 constata-se o predomínio de áreas com saldo hídrico em tonalidade verde. $\mathrm{O}$ déficit hídrico, entretanto, já pode ser observado localmente em algumas áreas (em vermelho e laranja) na porção centro-norte e leste do município, chegando a atingir $-12 \mathrm{mil} \mathrm{m}^{3} /$ ano, o que pode estar associado a situações de uso da água que excedem a disponibilidade. Uma atenção deve ser dada a estes agrupamentos de captações, bem como ao seu entorno, representado em tom amarelo por baixos valores de saldos hídricos em torno de 600 a 2000 $\mathrm{m}^{3}$ /ano, que podem sofrer influência das áreas sob estresse hídrico.

4.4 Recomendações para gestão de recursos hídricos subterrâneos

A constatação sobre a dificuldade de reunir séries históricas de dados cadastrais com informações de captações subterrâneas evidencia ser indispensável para a gestão de recursos hídricos a existência de bancos de dados que se relacionem ou consolidados em um único, com todas as

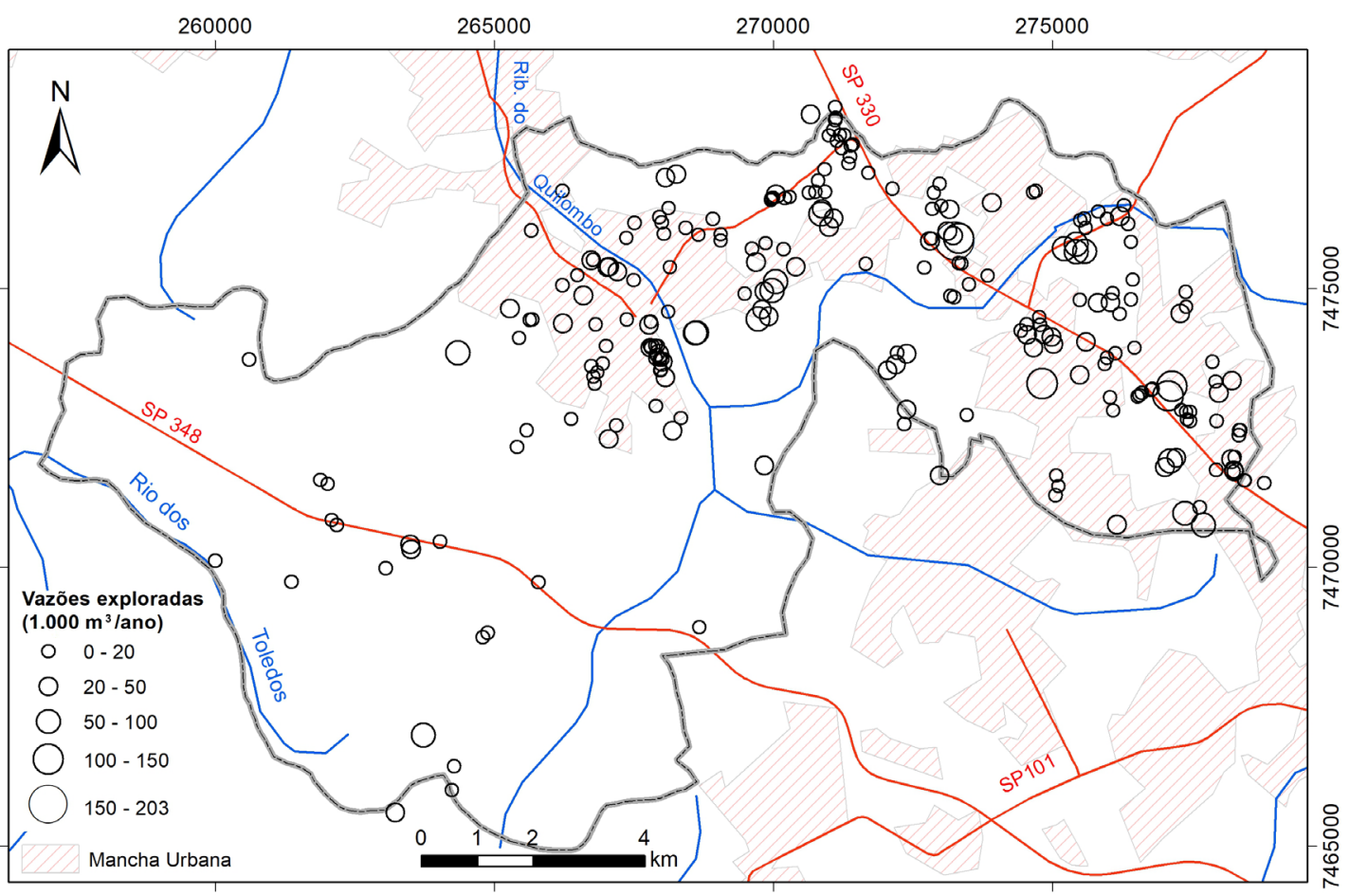

FIGURA 7 - Vazão anual extraída ( $\left.\mathrm{m}^{3} / \mathrm{ano}\right)$ por poços tubulares em Sumaré, com base nos dados de outorga. 


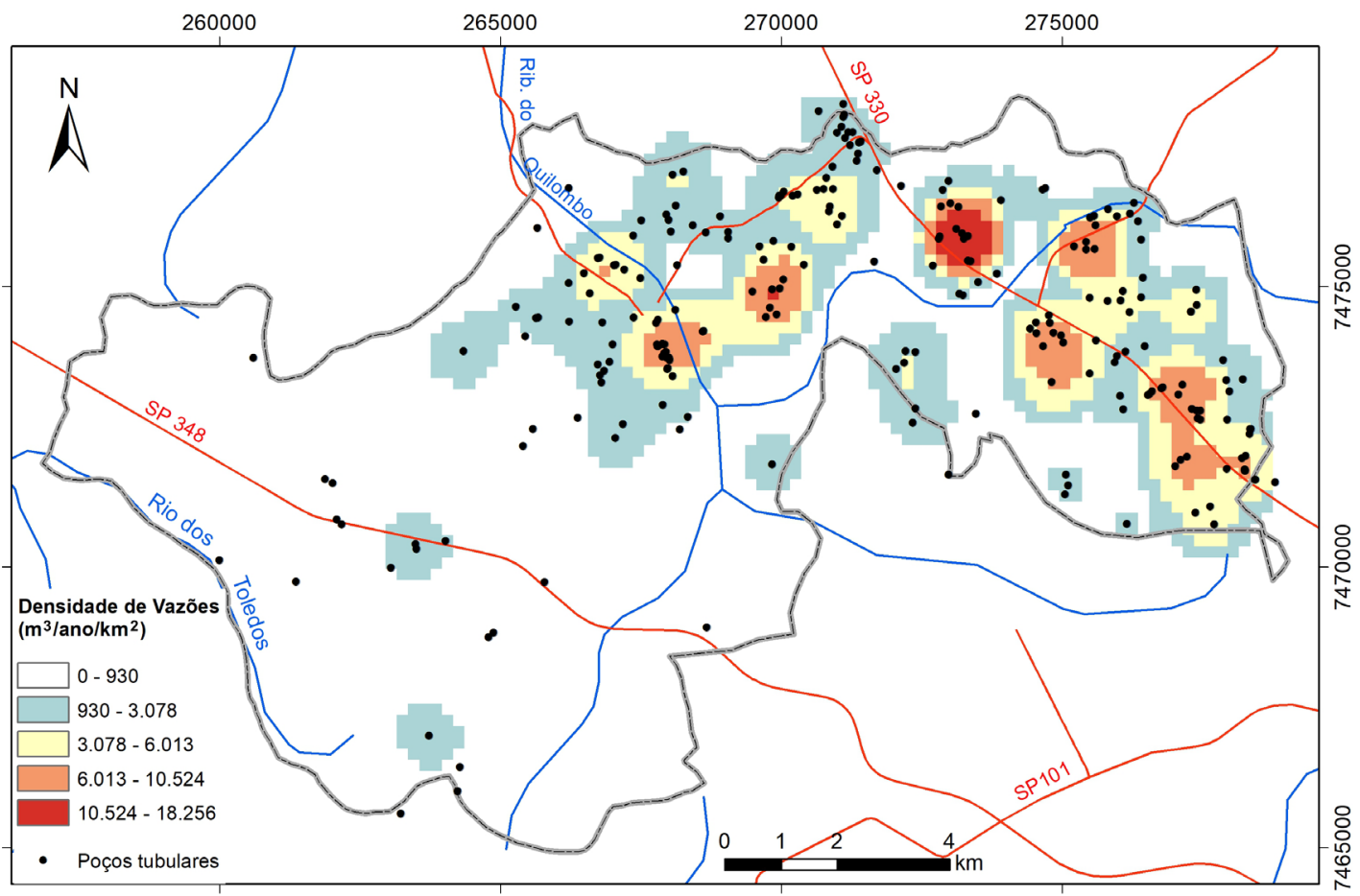

FIGURA 8 - Vazão anual especifica $\left(\mathrm{m}^{3} / \mathrm{ano} / \mathrm{km}^{2}\right)$ em Sumaré, determinada a partir da densidade de Kernel.

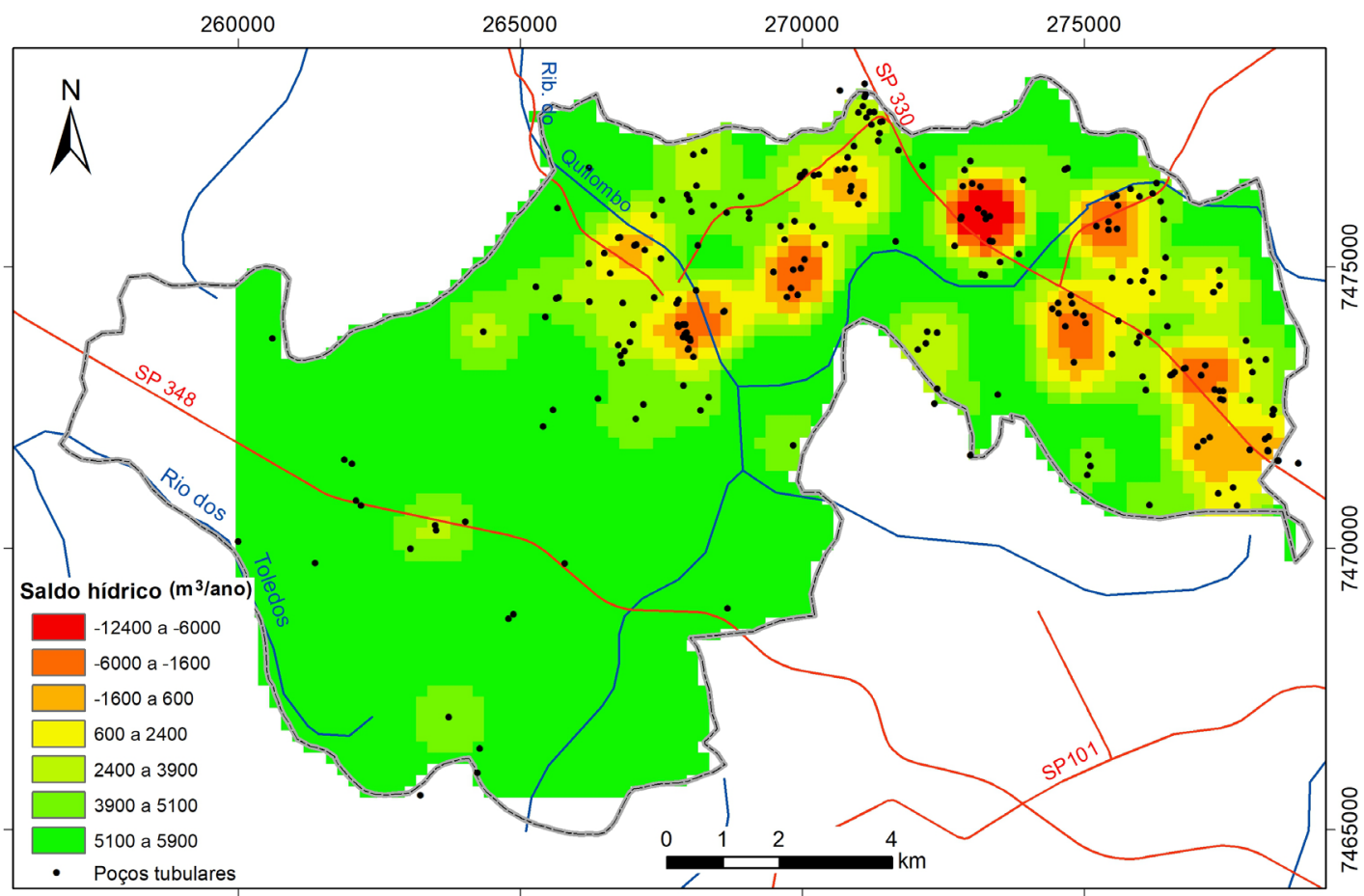

FIGURA 9 - Saldo hídrico nos aquíferos em Sumaré, com base nos dados de poços outorgados.

informações pertinentes: identificador comum, coordenadas geográficas e/ou coordenadas UTM, dados do teste de bombeamento, vazão e período outorgado, profundidade do poço, nível estático e dinâmico, aquífero explotado, data da perfuração, litologia, e, caso o poço encontre-se desativado temporariamente ou tamponado, o motivo para tal. As estimativas de potencialidade e produtivi- 
dade, uso e exploração de águas subterrâneas, situação do aquífero frente à explotação em áreas de maior exploração ou densidade de captações, entre outras informações, são obtidas a partir desses cadastros, o que justifica sua constante atualização e controle, inclusive, em nível municipal. O acesso a dados e informações confiáveis e seguros, portanto, são a base para o aprofundamento do conhecimento dos aquíferos, tanto quantitativa como qualitativamente, o que influirá diretamente na gestão de recursos hídricos.

Nesse sentido, recomenda-se que os órgãos gestores municipais organizem e atualizem um banco de informações e dados de poços, vinculado a um sistema de informações geográficas, que os auxilie no conhecimento sobre o uso e planejamento do uso de águas subterrâneas no município.

Esta ação é uma medida que contribuirá para a implementação do Plano Diretor Municipal, na medida em que ele prevê a incorporação da componente ambiental na definição dos critérios e parâmetros de uso e ocupação do solo, sobretudo para a proteção de mananciais e recursos hídricos.

Tendo em vista que o planejamento municipal prevê a implementação de polos de alta tecnologia, como por exemplo, indústrias de informática, telecomunicações, farmacêutica, biotecnologia, produtos eletrônicos, aeroespacial, indústrias criativas, entre outros (PREFEITURA MUNICIPAL DE SUMARÉ 2019c), é necessário que o zoneamento do município considere os aspectos de demanda e de disponibilidade hídrica, posto que entre os objetivos do Plano Diretor está a limitação do crescimento urbano em regiões não propícias à urbanização e naquelas de reconhecida qualidade ambiental a ser preservada ou restabelecida.

Os levantamentos e estudos hidrogeológicos devem ser considerados na elaboração e/ou atualização das diretrizes de um Plano de Gestão de Recursos Hídricos, visando apoiar os órgãos gestores na organização territorial prevista no Plano Diretor Municipal (PREFEITURA MUNICIPAL DE SUMARÉ 2006). Dentre as aplicações destes estudos, destacam-se os subsídios que podem fornecer à discussão e elaboração de mapas e zoneamento de áreas mais propícias ao uso e exploração da água subterrânea, assim como daquelas que implicarem alguma restrição à outorga do uso em função de superexploração comprovada.

Os dados sobre uso e exploração de águas subterrâneas em Sumaré demonstraram a necessidade de um acompanhamento nas áreas de maior densidade de poços e de maior concentração de volumes extraídos (outorgados), que correspondem às áreas em tonalidades vermelho-alaranjadas em Maria Antonia (AR-5), Nova Veneza (AR-2), Área Cura (AR-4), Matão (AR-3) e Sede (AR-1) (Figura 9), no sentido de averiguar a ocorrência de conflitos ou perdas de produtividade de poços, visando propor medidas de uso sustentável do recurso hídrico. O cenário observado no mapa de saldo hídrico é dinâmico e deve ser acompanhada sua evolução. Nesse sentido, recomenda-se o desenvolvimento de estudos que testem ou avaliem a proposta de distribuição de 4 poços por $\mathrm{km}^{2}$ (ODA et al. 2005), além de estudos e tratamentos estatísticos aprofundados relacionados à disponibilidade hídrica dos aquíferos, especialmente do Aquífero Tubarão, em Sumaré.

Outra ação complementar à atualização do banco de dados de poços nos municípios trata da regularização de captações não registradas, visando avaliar o consumo de água subterrânea e administrar a explotação em relação à disponibilidade (ANA 2018), o que implica no fortalecimento ou implantação de outra ação relacionada à fiscalização ambiental dos recursos hídricos.

Sempre que o objetivo for gestão, é necessário, também, considerar as ações não estruturais, como por exemplo, a educação ambiental, que deve ser realizada por meio de processo educativo, participativo e permanente, constituindo uma forma abrangente de educação, despertando a consciência crítica sobre a problemática da água e a evolução dos problemas ambientais. CONICELLI \& HIRATA (2016) destacam a importância da conscientização do usuário de água subterrânea nos seguintes aspectos: a) a água subterrânea como reserva estratégica que minimiza problemas de falta de água, e que não deve ser exaurida; b) a otimização do uso da água subterrânea que compatibiliza explotação e potencialidade aquífera; c) direito de acesso à água ao usuário regularizado; d) acesso a resultado de estudos sobre quantidade e qualidade da água dos aquíferos.

\section{CONSIDERAÇÕES FINAIS}

Nos municípios em que o abastecimento municipal em água é predominantemente baseado em captações superficiais, constata-se que a participação dos mananciais subterrâneos na produção de água também desempenha um importante papel e não deve ser desconsiderada. Em Sumaré, isso foi demonstrado pela quantidade de poços tubulares construídos na área urbana, com as finalidades de uso industrial e sanitário (serviços e comércio), o 
que demonstra crescimento da demanda por recurso hídrico desses setores.

Na região estudada, o Aquífero Tubarão é o mais explorado, estando a maior parte de poços localizados nas macrozonas urbana consolidada e fragmentada do município de Sumaré. Observam-se áreas com maior potencialidade (em termos de capacidade específica), que se encontram em pequenos bolsões na porção leste do município. Por outro lado, o levantamento e tratamento de dados referentes ao uso e exploração dos aquíferos em Sumaré demonstraram uma grande concentração de poços nas porções centro-norte e leste do município, caracterizando uma situação de atenção com relação à densidade de poços e aos volumes explorados $\left(\mathrm{m}^{3} /\right.$ ano), com indicação de áreas com déficit hídrico subterrâneo $\left(-12.400 \mathrm{~m}^{3} /\right.$ ano $)$, principalmente ao longo dos eixos de maior circulação (estradas e avenidas). A situação do aquífero em tais áreas de maior explotação (críticas) ou de maior densidade de captações deve ser acompanhada e estudada ao longo dos anos, com atenção a indícios de ocorrências de conflitos de uso, queda de produtividade dos poços, rebaixamentos de níveis d'água, etc.

Neste trabalho, os resultados obtidos fornecem indicativos de áreas menos favoráveis à perfuração de novos poços e servem de alerta para que os usuários verifiquem os locais onde se constata elevada concentração de poços associada a elevados volumes anuais (extraídos, outorgados).

Para a efetividade da gestão dos recursos hídricos subterrâneos em nível municipal sugere-se um aprofundamento dos estudos hidrogeológicos, bem como o registro de dados e informações históricas das perfurações de poços, visando apoiar os órgãos gestores na organização territorial prevista no Plano Diretor Municipal.

\section{AGRADECIMENTOS}

Aos Comitês PCJ pela concessão de bolsa de estudos no Curso de Especialização em Gerenciamento de Recursos Hídricos, da Fundação Municipal de Ensino de Piracicaba Pós-EPP/FUMEP. Ao geólogo Flávio de Paula e Silva pelas orientações no processamento de dados e mapas de saldo hídrico. Aos pareceristas da revista pelas sugestões que aprimoraram o artigo.

\section{REFERÊNCIAS}

ANA - AGÊNCIA NACIONAL DE ÁGUAS. 2018. Estudos hidrogeológico para a gestão das águas subterrâneas da região de Belém/ PA. Volume 3 - Plano de Gestão para as águas subterrâneas da região de Belém/PA. Elaboração e execução: Profill Engenharia e Ambiente S.A. ANA, Brasília, 110 p. (Relatório Final).

COMITÊS PCJ - COMITÊS DAS BACIAS HIDROGRÁFICAS DOS RIOS PIRACICABA, CAPIVARI E JUNDIAÍ. 2015. Relatório da situação dos recursos hídricos: versão simplificada: na base 2014. Parla, Piracicaba, 54 p. (Série UGRHI 05 - Bacias PCJ).

COMITÊS PCJ - COMITÊS DAS BACIAS HIDROGRÁFICAS DOS RIOS PIRACICABA, CAPIVARI E JUNDIAÍ. 2019. Relatório de situação dos recursos hídricos: versão simplificada, ano base 2018. Fundação Agência das Bacias PCJ, Piracicaba, 100 p. (Série UGRHI 05 - Bacias PCJ).

COMITÊS PCJ - COMITÊS DAS BACIAS HIDROGRÁFICAS DOS RIOS PIRACICABA, CAPIVARI E JUNDIAÍ. 2021. Relatório da situação dos recursos hídricos 2020: ano base 2019; versão simplificada. Fundação Agência das Bacias PCJ, Piracicaba, 131 p. (Série UGRHI 05 - Bacias PCJ).

CONICELLI, B.; HIRATA, R. 2016. Novos Paradigmas na Gestão das Águas Subterrâneas. In: ABAS, CONGRESSO BRASILEIRA DE ÁGUAS SUBTERRÂNEAS, 16, Campinas, Anais, 18 p.

CONICELLI, B.P.; HIRATA, R.; GALVÃO, P.; ARANDA. N.; TERADA, R.; GUTIÉRREZ, O.J.E. 2021. Groundwater governance: The illegality of exploitation and ways to minimize the problem. Anais da Academia Brasileira de Ciências, 93(1): e20200623. https://doi. org/10.1590/0001-3765202120200623

CRH - CONSELHO ESTADUAL DE RECURSOS HÍDRICOS. 2005. Deliberação CHR $n^{o} 52$, de 15/04/2005. Institui no âmbito do Sistema Integrado de Gerenciamento de Recursos Hídricos - SIGRH diretrizes e procedimentos para a definição de áreas de restrição e controle da captação e uso das águas subterrâneas.

CRH - CONSELHO ESTADUAL DE RECURSOS HÍDRICOS. 2011. Deliberação CRH $n^{\circ}$ 
132, de 19/04/2011. Homologa a Deliberação CBH-AT $n^{\circ} 01$ de 16 de fevereiro de 2011 que estabelece área de restrição e controle para a captação e uso das águas subterrâneas no município de São Paulo, na região de Jurubatuba, e dá outras providências.

CRH - CONSELHO ESTADUAL DE RECURSOS HÍDRICOS. 2014. Deliberação CRH $n^{\circ} 165$, de 09/09/2014. Referenda a Deliberação CBH-PARDO n $^{\circ} 201$, de 01 de agosto de 2014 que retiratifica a Deliberação 171 de 22 de junho de 2012 que "Redefine Critérios Técnicos para a Autorização de Perfuração de Poços Tubulares Profundos no Município de Ribeirão Preto".

DAEE - DEPARTAMENTO DE ÁGUAS E ENERGIA ELÉTRICA. 1981. Estudo de Águas Subterrâneas - Região Administrativa 5 - Campinas. DAEE, São Paulo, 2 v.

DAEE - DEPARTAMENTO DE ÁGUAS E ENERGIA ELÉTRICA. 2015a. Diagnóstico hidrogeológico e elaboração de propostas para a gestão dos recursos hídricos subterrâneos no municipio de Bauru. DAEE, Bauru/ SP, 159 p. (Relatório Final).

DAEE - DEPARTAMENTO DE ÁGUAS E ENERGIA ELÉTRICA. 2015b. Diagnóstico hidrogeológico e elaboração de propostas para a gestão dos recursos hídricos subterrâneos no eixo Jacareí - São José dos Campos - Caçapava no Estado de São Paulo. DAEE, UGRHI 2/SP, $221 \mathrm{p}$.

DAEE/IG/IPT/CPRM - DEPARTAMENTO DE ÁGUAS E ENERGIA ELÉTRICA/INSTITUTO GEOLÓGICO/INSTITUTO DE PESQUISAS TECNOLÓGICAS/ COMPANHIA DE PESQUISA DE RECURSOS MINERAIS. 2005. Mapa de Águas Subterrâneas do Estado de São Paulo. Escala 1:1.000.000. Nota explicativa. DAEE/IG/ IPT/CPRM, Sâo Paulo, 3 v. (mapa e CD$-\mathrm{ROM})$.

\section{DAEE/UNESP - DEPARTAMENTO DE ÁGUAS E ENERGIA ELÉTRICA/UNIVERSIDADE ESTADUAL PAULISTA. 2013. Águas Sub- terrâneas no Estado de São Paulo. Diretrizes de Utilização e Proteção. DAEE/LEBAC, São Paulo, 44 p.}

FRACALANZA, A.P.; FREIRE, T.M. 2016. Crise da água na Região Metropolitana de São Paulo: injustiça ambiental, privatização e mercantilização de um bem comum. GEOUSP - Espaço e Tempo, 19(3): 464-478. https://doi.org/10.11606/issn.2179-0892. geousp.2015.103064

FOSTER, S.; HIRATA, R.; HOWARD, K. 2011. Groundwater use in developing cities: policy issues arising from current trends. Hydrogeology Journal, 19: 271-274. https:// doi.org/10.1007/s10040-010-0681-2

HIDROGEOAMBIENTAL. 2019. Estudo de avaliação hidrogeológica visando à captação de água subterrâneas - Produto 4. Agência Bacias PCJ, Piracicaba, 767 p. (Relatório final). Disponível em http://www.agencia. baciaspcj.org.br/docs/projetos/estudos-avaliacao-hidrogeologica.pdf. Acessado em 13 jul. 2019.

IBGE - INSTITUTO BRASILEIRO DE GEOGRAFIA E ESTATÍSTICA. 2019. Sumaré. Disponível em https://www.ibge.gov.br/cidades-e-estados/sp/sumare.html. Acessado em 04 dez. 2019.

IG - INSTITUTO GEOLÓGICO. 2013. Identificação de áreas potenciais de restrição e controle de captação e uso das águas subterrâneas na porção sul da UGRHI 05 - PROJETO $A R C$-TUB1. Reimpressão, IG, São Paulo, 2 vols.

IRITANI, M.A.; ODA, G.H.; EZAKI, S.; VARNIER, C.L. 2009. Delimitação de área de Proteção das Águas Subterrâneas no Município de Capivari (SP). Revista do Instituto Geológico, 30(1/2): 1-18. http://dx.doi. org/10.5935/0100-929X.20090001

ODA, G.H.; TAKEUCHI, D.M.; EZAKI, S.; IRITANI, M.A.; VARNIER, C.; PENTEADO, D.; LIMA, C.V.F.; SILVA, A.H.; ZUCA, N.L.; PACHECO, R.P. 2012. Geometria do Aquífero Tubarão entre os municípios de Indaiatuba e Capivari (SP). Revista do Instituto Geológico, 33: 23-40. http://dx.doi. org/10.5935/0100-929X.20120002

ODA, G.H.; IRITANI, M.A.; FERREIRA, L.M.R.; SILVA, A.H.; ROCHA, G.A. 2005. Proposta metodológica para explotação racional do 
Sistema Aquífero Tubarão no Estado de São Paulo. In: ABAS, ENCONTRO NACIONAL DE PERFURADORES DE POÇOS, 14 / SIMPÓSIO DE HIDROGEOLOGIA DO SUDESTE, 2, Ribeirão Preto, Anais, 13 p.

PAULA E SILVA, F.P.; FISCHER, T.; EZAKI, S.; GASTMANS, D.; RODRIGUES, V.R.; ALBUQUERQUE FILHO, J.L; FRANZINI, A.S.; NOALE, J.O. 2021. Avaliação do Estresse Hídrico Subterrâneo nas Bacias dos Rios Piracicaba, Capivari e Jundiaí. Derbyana, 42: e754. https://doi.org/10.14295/derb. v42.754

PREFEITURA MUNICIPAL DE SUMARÉ. 2006. Plano Diretor. Lei $N^{\circ} 4250$, de 6 de Outubro de 2006. Câmara Municipal de Sumaré, Sumaré. Disponível em https://legislacaodigital.com.br/Sumare-SP/LeisOrdinarias/4250-2006. Acessado em 15 jul. 2019.

PREFEITURA MUNICIPAL DE SUMARÉ. 2019a. Revisão do Plano Diretor do Município de Sumaré/SP, 2019-2039. Volume 1 - Leitura do Município. Secretaria Municipal de Planejamento, Desenvolvimento e Gestão Estratégica - SEPLAN, Sumaré. Disponível em https://www.sumare.sp.gov. br/plano_diretor/arquivos/mapVol1/VOLUME01COMPLETO.pdf. Acessado em 12 nov. 2021.

PREFEITURA MUNICIPAL DE SUMARÉ. 2019b. Revisão do Plano Diretor do Municipio de Sumaré/SP, 2019-2039. Volume 4. Secretaria Municipal de Planejamento, Desenvolvimento e Gestão Estratégica - SEPLAN, Sumaré. Disponível em https://www.sumare. sp.gov.br/plano_diretor/. Acessado em 12 nov. 2021.

PREFEITURA MUNICIPAL DE SUMARÉ. 2019c. Revisão do Plano Diretor do Município de Sumaré/SP, 2019-2039. Volume 2 - Aspectos Espaciais - Estrutura Urba$n a$. Secretaria Municipal de Planejamento, Desenvolvimento e Gestão Estratégica - SEPLAN, Sumaré. Disponível em https://www.sumare.sp.gov.br/plano_diretor/ arquivos/mapVol2/VOLUME\%2002\%20-\%20(Atualizado).pdf. Acessado em 12 nov. 2021.
PROFILL - PROFILL ENGENHARIA E AMBIENTE S.A. 2019. Plano de monitoramento quali-quantitativo das águas subterrâneas da Bacias PCJ. Produto 2-V03 - Diagnóstico Hidrogeológico das Bacias PCJ. Agência das Bacias PCJ, Piracicaba, 199 p.

SABESP - COMPANHIA DE SANEAMENTO BÁSICO DO ESTADO DE SÃO PAULO. 2017. Norma técnica SABESP NTS $181-D i$ mensionamento do ramal predial de água, cavalete e hidrômetro - Primeira ligação revisão 4. São Paulo/SP, p. 23. Disponível em http://www2.sabesp.com.br/normas/nts/ NTS181.pdf. Acessado em 18 jan. 2020.

SANTOS, M.D. 2013. O papel dos municípios na gestão dos recursos hídricos: estudo de caso sobre o município de Rio Acima/MG. Monografia, Curso de Especialização em Gerenciamento de Recursos Hídricos, Instituto de Ciências Biológicas, Universidade Federal de Minas Gerais, Belo Horizonte, $41 \mathrm{p}$.

SERVMAR/DAEE/IG - SERVMAR/DEPARTAMENTO DE ÁGUAS E ENERGIA ELÉTRICA/INSTITUTO GEOLÓGICO. 2011. Projeto São José do Rio Preto - Restrição e Controle de Uso de Água Subterrânea. São Paulo: DAEE/IG, 142 p. (Cadernos do Projeto Ambiental Estratégico Aquíferos, 4).

SNIS - SISTEMA NACIONAL DE INFORMAÇÕES SOBRE SANEAMENTO/MINISTÉRIO DO DESENVOLVIMENTO REGIONAL. 2020. Municipio: Informações e indicadores municipais consolidados. SNIS-Série Histórica, Secretaria Nacional de Saneamento. Disponível em http://app4.cidades. gov.br/serieHistorica/. Acessado em 19 jan. 2020 .

SOUZA, L.C. 2012. O munícipio como partícipe na proteção das águas subterrâneas no Brasil. Boletín Geológico y Minero, 123(3): 377388.

SOUZA FERNANDES, L.C. 2015. Breve panorama da escassez de água nas bacias hidrográficas do Alto Tietê e do PCJ. Labor \& Engenho, 9(4): 51-65. https://doi.org/10.20396/ lobore.v9i4.8642026 
Endereço dos autores:

Thalita Benetello - Departamento de Águas e Energia Elétrica, Diretoria da Bacia do Médio Tietê DAEE/BMT, Rua Cristiano Cleopath, 1557, Bairro dos Alemães, Piracicaba, SP, Brasil. E-mail: thalita. benetello@daee.sp.gov.br

Sibele Ezaki - Instituto de Pesquisas Ambientais, Secretaria de Infraestrutura e Meio Ambiente/SP, Rua Joaquim Távora, 822, Vila Mariana, CEP: 04015-011, São Paulo, SP, Brasil.E-mail: sibezaki@sp.gov.br Artigo recebido em 9 de julho de 2021, aceito em 10 de dezembro de 2021. 